This item was submitted to Loughborough's Research Repository by the author.

Items in Figshare are protected by copyright, with all rights reserved, unless otherwise indicated.

\title{
Drivers' information requirements when navigating in an urban environment
}

PLEASE CITE THE PUBLISHED VERSION

PUBLISHER

(C) Cambridge University Press

LICENCE

CC BY-NC-ND 4.0

\section{REPOSITORY RECORD}

May, Andrew, Tracy Ross, and Steven H. Bayer. 2019. "Drivers' Information Requirements When Navigating in an Urban Environment". figshare. https://hdl.handle.net/2134/2637. 


\title{
Drivers' Information Requirements when Navigating in an Urban Environment
}

\author{
Andrew J. May, Tracy Ross and Steven H. Bayer \\ (Loughborough University)
}

\begin{abstract}
Navigating in unfamiliar road environments is a common and demanding cognitive activity. If this cannot be accomplished successfully, there are implications for increased driver workload, delays due to navigation errors, potentially unsafe road behaviour such as late lane changes, and inappropriate traffic management. To enable successful navigation through such environments, it is necessary to understand what the navigation task entails, and what a driver's corresponding information requirements are. This paper reports the results of a study that sought to identify what information is used by drivers when navigating within a range of urban driving environments, how this information is used, and what the implications are for the design of navigation aids.
\end{abstract}

\section{KEY WORDS}

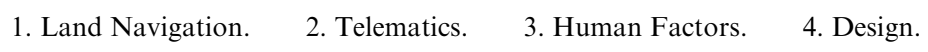

1. INTRODUCTION. The task of navigating in unfamiliar road environments is a common and difficult activity for drivers. Considerable cognitive effort is required, in addition to the normal demands associated with driving in complex and busy traffic environments (Burnett, 2000). Research dating back over a decade has demonstrated the problems that drivers have in planning and following efficient routes to destinations (King, 1986; Streeter, 1986; Wierwille et al., 1989). If efficient routes cannot be planned and easily followed, the consequences are stress, frustration and delays for the driver resulting from navigation errors, potentially unsafe road behaviour (e.g. late lane changes) and inappropriate traffic management (e.g. traffic diversions through small villages).

Irrespective of the particular navigation environment and the mode of travel, there are some basic navigational needs:

(a) Planning a route.

(b) Identifying potential navigation decision points.

(c) Undertaking decisions where presented with navigational uncertainty.

(d) Confirming that correct navigation decisions have been taken.

(e) Maintaining confidence throughout the journey.

(f) Developing an awareness of orientation where necessary.

(g) Identifying the arrival at a destination.

Of course, many strategies can be employed for navigating a route successfully. From a driver's perspective, the least complex and demanding would be to follow either 


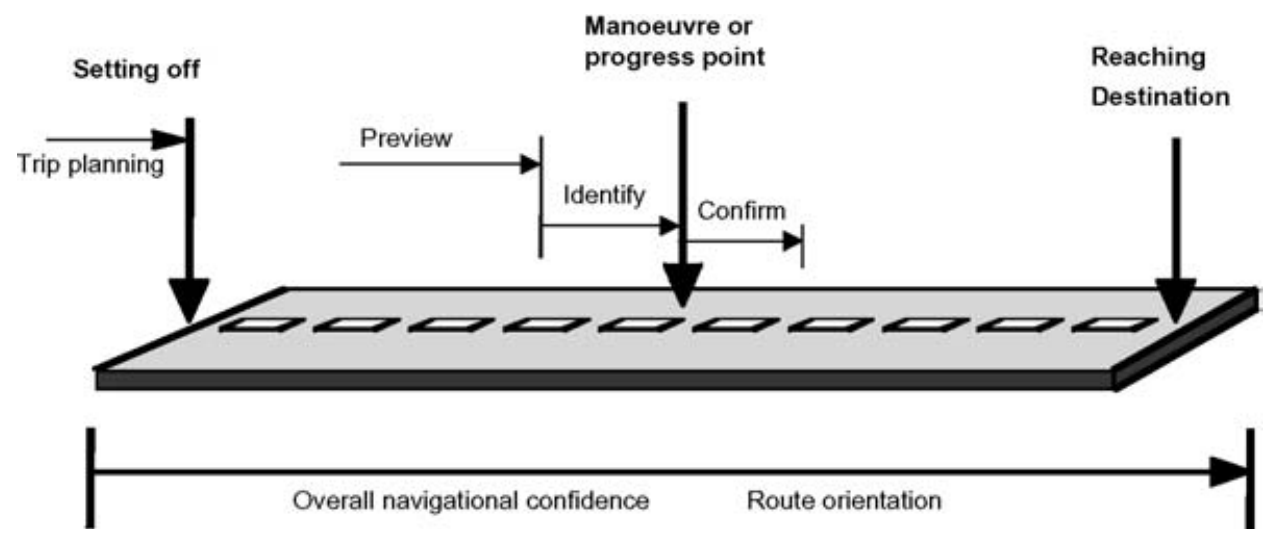

Figure 1. A task-based model of navigation (after Burnett, 1998).

(1) another vehicle or (2) basic turn instructions from a passenger. Both of these strategies would negate much of the cognitive demand normally associated with navigation. However, in most cases, a driver in an unfamiliar environment will be required to use the information within that environment to make navigational decisions, and this will occur independently of the particular navigation aid that is being employed. Within a complex urban environment, the potential information cues available are many and varied, but even so, it is likely that only a small subset of this information will be used by navigators. The focus of this paper is understanding what those information cues are, and how and when they are used within a complex urban navigation context, without being influenced by the constraints of any particular navigation aid.

1.1. Understanding the driver's navigation task. There are many different theoretical models that attempt to describe the navigation task from a driver's perspective. Burns (1997) describes a theoretical model of wayfinding based on the use of a driver's cognitive map and short and long term memory, plus information cues from the environment, to resolve navigational uncertainty. This model is based on the information processing model of Wickens (1992), but also adapted to take into account wayfinding theories such as those proposed by Chown (1995), Passini (1984) and others. In contrast, Zhai (1991) describes a behavioural model that explicitly accounts for the interactions between the driver, a navigational aid, vehicle and the environment. Although more complex, this model is not so conducive to a technologyindependent view, since it makes explicit reference to aspects of navigation system design. Mark (1989) presents a conceptual view of a vehicle navigation 'system', involving a geographic database, vehicle and destination positioning, route planning, instruction generation and vehicle control. This model allows a technology independent consideration of the functions needed for successful vehicle navigation. Burnett (1998) describes a model, which focuses on the temporal nature of the navigation task, and identifies the basic information requirements for each of the navigation stages. A slightly adapted version of this model is shown in Figure 1.

Since the purpose of the study reported in this paper was to focus on the information required for successful navigation, independent of any navigation aid and the concurrent driving demands, the model shown in Figure 1 was used as one method of organising and categorising information requirements. 
Table 1. Main research questions.
1 What information is used by drivers for navigation purposes?
2 How is that information described?
3 Which aspects of the navigation task does the information support?
4 How important is that information in enabling key navigation objectives?
5 How does information map onto the main characteristics of a route?

1.2. Research Questions. The study described in this paper sought to understand the information requirements for a driver navigating through a range of urban driving environments. Specifically, there were five research questions posed at the beginning of the study, shown in Table 1. These enable an understanding of the driver's navigational task, and also have direct implications in terms of designing potential navigation aids.

\section{METHOD.}

2.1. Overview. The study described in this paper is an empirical requirements study, where participants were presented with a series of demanding urban routes, and asked to identify the information that they felt a driver, unfamiliar with those routes, would need to navigate them successfully. This study employed a similar methodology to that used successfully in a previous pilot study involving 32 participants (Burnett et al., 2001). With any requirements study, there are several methodological issues relating to the requirements capture process, for example: selecting the 'users' (who will be generating your data?); defining the task (what will the users do to generate the data?); representing the necessary characteristics of the navigation scenario (what information will be used to generate data?); capturing the output of the process; and generalising the results (i.e. making them useful outside the bounds of a particular study).

Within the study reported here, a basic assumption was made that the best navigation cues were those that were visually prominent, and/or those that were identified by individuals with extensive local knowledge (reflecting the recognised importance of mental representations of spatial environments (Christou and Bulthoff, 2000)). For this reason, an approach was taken involving two different and complementary methodological approaches. One participant group (termed the 'video' group) had no knowledge of the area, and viewed a video image of the routes - the navigation information identified by this group was therefore based purely on the visual representation of potential navigation cues along the route. The other participant group (termed the 'cognitive map' group) had extensive local knowledge of the area (they had all lived or worked in the area for at least five years). This group used schematics of the routes that were designed to provide just enough information to inform the participants of the required route, but not to provide any further information such as road names/ numbers, junction layouts, geographical features etc.

These different approaches had associated advantages and disadvantages as shown in the Table 2. For a fuller discussion of the relative merits of different types of information sources used within such requirements studies, see Burnett (1998).

2.2. Participants. A total of 36 participants took part in the study, with 13 males and 5 females in each group. Participants were selected such that within each condition (video or cognitive map) there was a range of ages within three age groups (20-34, $35-49,50+$ ). Participant ages were therefore matched across the different groups, with 
Table 2. Comparison of different information sources for direction giving studies.

\begin{tabular}{|c|c|c|}
\hline Information based on: & Advantages: & Disadvantages: \\
\hline $\begin{array}{l}\text { Single visual experience } \\
\text { of the route via a video }\end{array}$ & $\begin{array}{l}\text { Based on direct observation: } \\
\text { the view of an unfamiliar } \\
\text { traveller }\end{array}$ & $\begin{array}{l}\text { A 'snap-shot' experience of } \\
\text { routes: therefore, limited by } \\
\text { specific views available, } \\
\text { time of day etc. }\end{array}$ \\
\hline $\begin{array}{l}\text { Long-term experience of } \\
\text { the area based on the } \\
\text { memory of locals }\end{array}$ & $\begin{array}{l}\text { Based on repeated exposure to } \\
\text { landmarks - information } \\
\text { used by 'expert' navigators }\end{array}$ & $\begin{array}{l}\text { Individual's memory for } \\
\text { landmarks prone to } \\
\text { subjective biases }\end{array}$ \\
\hline
\end{tabular}

Table 3. Route details.

\begin{tabular}{llcc}
\hline Route & Characteristics & $\begin{array}{c}\text { Typical traffic } \\
\text { speeds }\end{array}$ & $\begin{array}{c}\text { No. of main } \\
\text { decision points }\end{array}$ \\
\hline 1. City centre & $\begin{array}{c}\text { Retail, central business district, } \\
\text { one way streets } \\
\text { Built up, single \& dual } \\
\text { 2arriageway, ring road } \\
\text { Out of town, fast single \& dual } \\
\text { 3. Out of town }\end{array}$ & $<50 \mathrm{kph}$ & 12 \\
\hline
\end{tabular}

a mean age of 34 years $(\mathrm{SD}=13 \cdot 1)$ for the cognitive map subjects and a mean age of 36 years $(\mathrm{SD}=9 \cdot 2)$ for the video subjects. All participants in the video condition had no prior knowledge of the test routes concerned; all cognitive map participants had extensive local knowledge. All participants had driven regularly for at least two years: this requirement was placed on participants to ensure that they were able to identify navigationally relevant information.

2.3. Routes. Three different complex routes were used as outlined in Table 3 . These were based in and around the city of Coventry (population approximately 300000 ) located in the Midlands region of the UK. Researchers such as Burnett (1998) have highlighted the importance of the route used within studies of this nature, as this determines the type and amount of information available. In addition, there are recommendations that demanding routes are chosen, as these increase the difficulty of the navigation task, and consequently increase the need for the provision of accurate information.

A decision point was analogous to a node within a path/node network, and was defined as a point at which a driver would normally require navigation information (see Section 2.5).

All three routes were filmed using a digital video recorder with a focal length of $38 \mathrm{~mm}$. This generated an image with a sufficiently wide angle of view to include a clear view of all side roads and junction exits, with a resolution such that most of the road signs and street names were clearly visible. This was used for participants in the video condition. For the cognitive map participants, a schematic was developed for the routes, based initially on a street atlas. These schematics clearly labelled the start and end points for each route, and provided sufficient road layout information to enable the participants to understand the required route. All other information was removed.

2.4. Procedure. Participants were informed that the general nature of the study was to investigate how people navigate within a range of environments. Throughout 
the trial, no specific mention of any particular navigation cues was made in order to reduce bias towards particular types of information. Initial questionnaires were completed that consisted of sections detailing participant demographics, driving experiences and typical navigation strategies. Due to space limitations, the questionnaire results are not included in this paper.

Participants were told that they were to provide written directions to enable a driver, totally unfamiliar with the particular routes, to navigate those routes successfully. Participants were told that these directions could take any form, and could include any information that was deemed necessary, but could consist only of written directions and could not include any diagrams. This requirement was stipulated to ensure that explicit reference was made to aspects of the route, and to identify the terminology used for particular information items.

The participants in the video condition viewed a video, and wrote down their instructions based on this video, for each route in turn. They were able to rewind and replay the video as many times as they wanted, until they were happy with the instructions they had generated. If there were any aspects of the video that were not clear (e.g. if any of the road signs or street names were obscured or indistinct), the participants could ask the experimenter for clarification. The participants in the cognitive map condition were provided with a route schematic, and wrote down their directions for each route in turn. There was no time limit placed on either participant group. When the participants had completed all three routes, they also completed an embedded figures psychometric test to assess their field dependency; these results are not reported in this paper. All participants were then de-briefed, and paid for their time.

2.5. Data analysis and coding. The written instructions generated by the 36 participants were analysed in detail and each reference to a navigation information item was identified. There were approximately 800 different information items referred to by participants; each one was analysed as follows:

2.5.1. Information category. A three-tier coding categorisation was used to identify the type of navigation information used by participants, this being based on the results of pilot studies, and a categorisation scheme developed by Burnett (1998). A general code was used to identify the type of information; Table 4 shows the top-level categorisation of navigation information. The issue of what constitutes a landmark is potentially problematic; following the approach taken in much of the literature, the definition of a landmark included buildings (e.g. post offices), street furniture (e.g. traffic lights) and built aspects of the environment (e.g. bridges), but excluded geographical features such as hills and bends in the road, and also street signs.

2.5.2. Information description. For each participant, reference to a piece of navigation information, the actual wording used by the participant to refer to that information was recorded. A distinction was made between the same object being referred to by using different information categories, and different wording being used within a particular category. For example, a particular road could be referred to using the GP, RT or SNN categories in Table 4, and was coded accordingly. Within each of those categories, that same object could be referred to in several ways: within the RT category, multiple descriptions were possible, e.g. 'dual carriageway', 'main road'.

2.5.3. Information to support the navigation task. Figure 1 shows the basic model of navigation that was used to understand and categorise the information requirements for a driver. In relation to each manoeuvre or progress points, information was categorised as follows: Preview information was that used to give the driver advance 
Table 4. Main information categories.

\begin{tabular}{|c|c|c|}
\hline Specific code & General information type & Example \\
\hline DSN & $\begin{array}{l}\text { Direction sign used for its navigation } \\
\text { information. }\end{array}$ & $\begin{array}{l}\text { Follow the signs for city } \\
\text { centre. }\end{array}$ \\
\hline DSO & Direction sign used as a navigation object. & Left at the motorway sign. \\
\hline DIST & $\begin{array}{l}\text { Distance, referred to in qualitative or } \\
\text { quantitative terms. }\end{array}$ & $\begin{array}{l}300 \text { metres; quite a long } \\
\text { way. }\end{array}$ \\
\hline EN & $\begin{array}{l}\text { Environment, describing a geographical } \\
\text { region or area. }\end{array}$ & $\begin{array}{l}\text { Residential; commercial; } \\
\text { industrial. }\end{array}$ \\
\hline $\mathrm{JN}$ & Junction type, a driver main decision point. & $\mathrm{T}-$ junction; crossroads. \\
\hline JNN & Junction name or number. & J. 27; Redhill Roundabout. \\
\hline $\mathrm{LM}$ & $\begin{array}{l}\text { Landmark, an object or building referred to, } \\
\text { coded according to category. }\end{array}$ & $\begin{array}{l}\text { Pubs; post offices; traffic } \\
\text { lights; bridges. }\end{array}$ \\
\hline $\mathrm{LC}$ & Lane positioning or lane changing instruction. & Stay in/get in left lane. \\
\hline GN & $\begin{array}{l}\text { Geometry of node, a descriptor applied to a } \\
\text { junction or manoeuvre. }\end{array}$ & Sharp; veer. \\
\hline GP & Geometry of path, a descriptor applied to a road. & Bendy; straight. \\
\hline $\mathrm{RM}$ & $\begin{array}{l}\text { Road marking, any information on the } \\
\text { road surface. }\end{array}$ & Dotted line; give way. \\
\hline RT & Type of road, according to visual appearance. & Ring road; dual carriageway. \\
\hline SNN & Street name/number. & Holyhead Road; A423. \\
\hline TM & $\begin{array}{l}\text { Time, referred to in qualitative or quantitative } \\
\text { terms. }\end{array}$ & 5 minutes; for a while. \\
\hline
\end{tabular}

warning that a manoeuvre (or progress point) is coming up: it is information that is preparatory to that manoeuvre or progress point. Examples would be 'you will be turning left in $100 \mathrm{~m}$ ' and 'move into the left hand lane as you approach the roundabout'. Information coded as identify is used to pinpoint an exact point on route, for example 'turn left at the traffic lights' and 'go round a sharp bend'. Confirm information, usually described in relation to manoeuvres, is used to confirm that the driver has accomplished that aspect of the task successfully (e.g. has taken the correct turning). Examples are 'turn right into Blake Drive' and 'take the second exit off the roundabout, going under the bridge'.

2.5.4. Information importance. All information items were coded according to whether they were being used as primary or secondary information. Primary information was defined as that which the driver must receive in order for them to complete the manoeuvre or identify a particular point on the route. If primary information were removed from the navigation instructions, it would make it impossible to complete, or create substantial driver uncertainty about, the navigation task. Examples would be 'turn left after $300 \mathrm{~m}$ ', or 'turn right at the mini roundabout'. Secondary information was defined as information that the driver does not necessarily need in order for them to complete the manoeuvre or identify a progress point on the route, but that aids the navigation task. This is information that is partially redundant and whilst it may aid navigation, or increase navigational confidence, it could be removed whilst still enabling the manoeuvre or progress point to be identified. Examples would be 'turn left at the first set of traffic lights in $300 \mathrm{~m}$ ', or 'turn right at the roundabout, sign posted to Birmingham'.

2.5.5. Information in relation to route characteristics. A detailed route description was developed that identified where information was used in relation to the main driver 


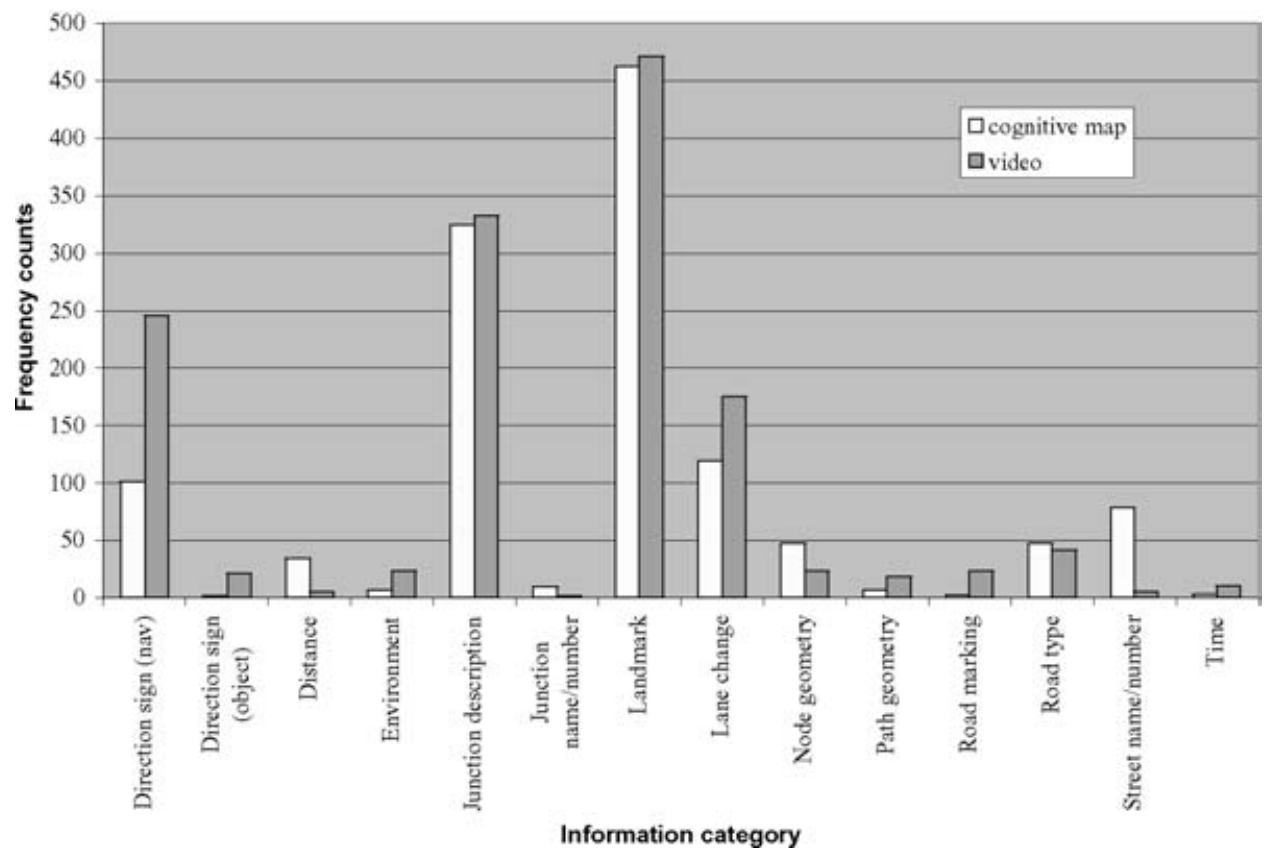

Figure 2. Total frequency of reference to general information categories by the video and cognitive map participants.

decision points. A distinction was made between manoeuvre points, and progress points; in general, these refer to nodes and paths respectively, with a few provisos. A manoeuvre was defined as a point on the route where there is a potential navigation decision, for example a left or right turn, an exit at a roundabout, going straight on at a set of traffic lights. It could be argued that each time a driver passes even a minor road off the road they are travelling along, they have to make a navigation decision to continue on the present road. However, it would have proved impractical to code all such points on the routes, a driver would normally just continue unless told otherwise, and any navigational aid would be unlikely to refer to all such minor turns. Therefore manoeuvres were defined such that they excluded points on the route where there is just one right of way AND the driver is following that right of way. In practice, a manoeuvre is a point where a driver would expect some navigation information at a point of driver uncertainty. In contrast, a progress point was defined as a point on the route where there is no potential manoeuvre, and that progress point is being identified in order to locate the driver relative to the route and provide confidence that they following the correct route, i.e. progress points are those sections of the route between manoeuvres. Examples would be 'continue up the hill' and 'go past the pub on your right'.

\section{RESULTS.}

3.1. Information category. It was expected that a wide range of different information types would be used to help navigation, given such a diverse road environment. Figure 2 shows the total number of references to different categories of information, 


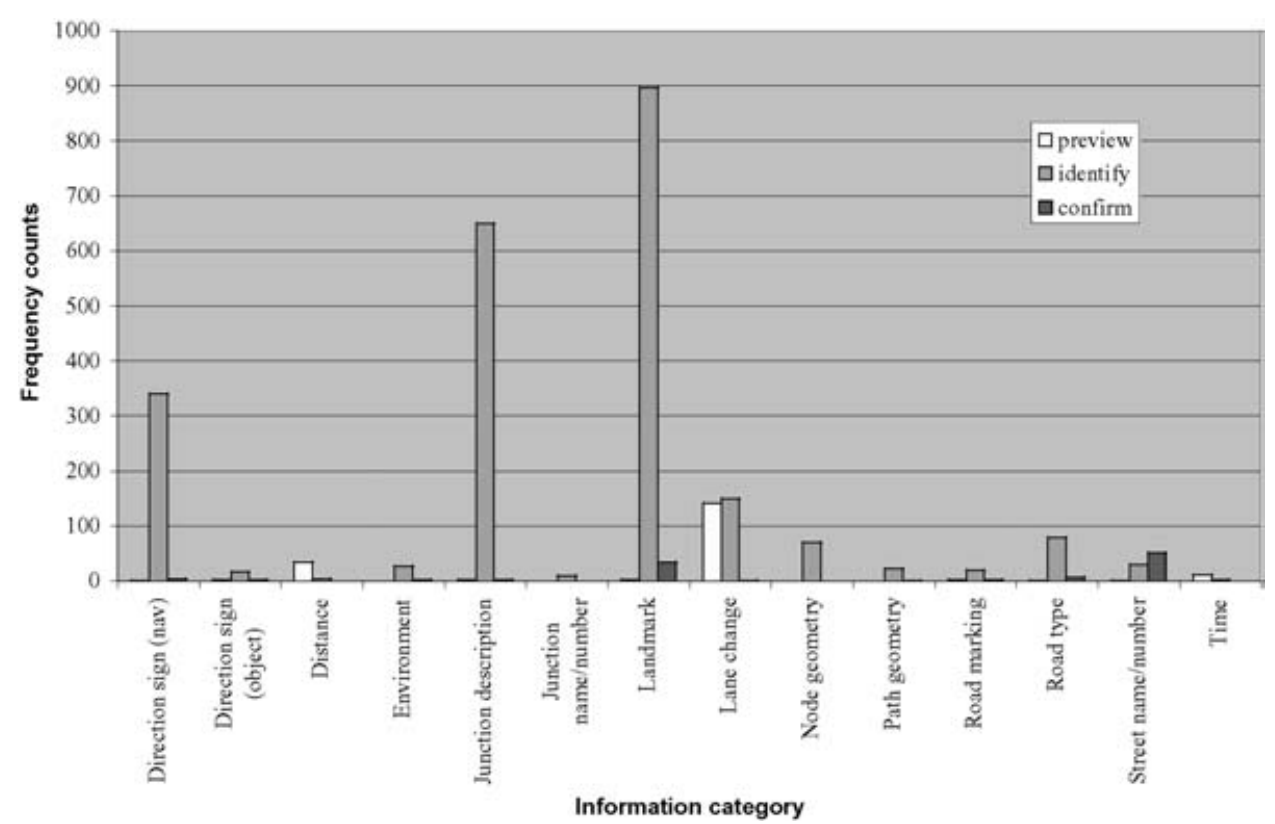

Figure 3. The use of general information categories to preview, identify or confirm a manoeuvre or progress point, for all participants.

split according to whether information was identified by the video or cognitive map participants.

3.2. Information description. A detailed results presentation is beyond the scope of this paper. However, participants commonly used several different descriptions to refer to the same information. For example, an official building en-route that was the 'Council House' was also described as a 'church', 'registry office' and 'town hall', and a particular 'Y' junction was typically also described as 'road forks', 'road branches', or 'road bears left'. For landmarks in particular, a wide range of descriptions were used; these included references to the form (what it looked like), function (what it was) and label (what it was called).

3.3. Information to support the navigation task. For each reference to a piece of navigation information, a judgement was made as to which aspect of the navigation task the information was being used for, and in particular whether the information was being used to provide preview information, identify the manoeuvre or progress point, or as confirmation. Figure 3 shows the frequency with which general information categories were used by all participants to preview, identify or confirm each manoeuvre or progress point.

3.4. Information importance. It was expected that a considerable degree of redundancy would be employed within the navigation instructions generated, i.e. that some information would be vital in terms of enabling a driver to navigate the routes, whilst other information would be redundant to some extent. This redundant information is helpful to the driver, but not necessarily required. Figure 4 shows the frequency with which general information categories were used by all participants as primary (required) or secondary (redundant) information. 


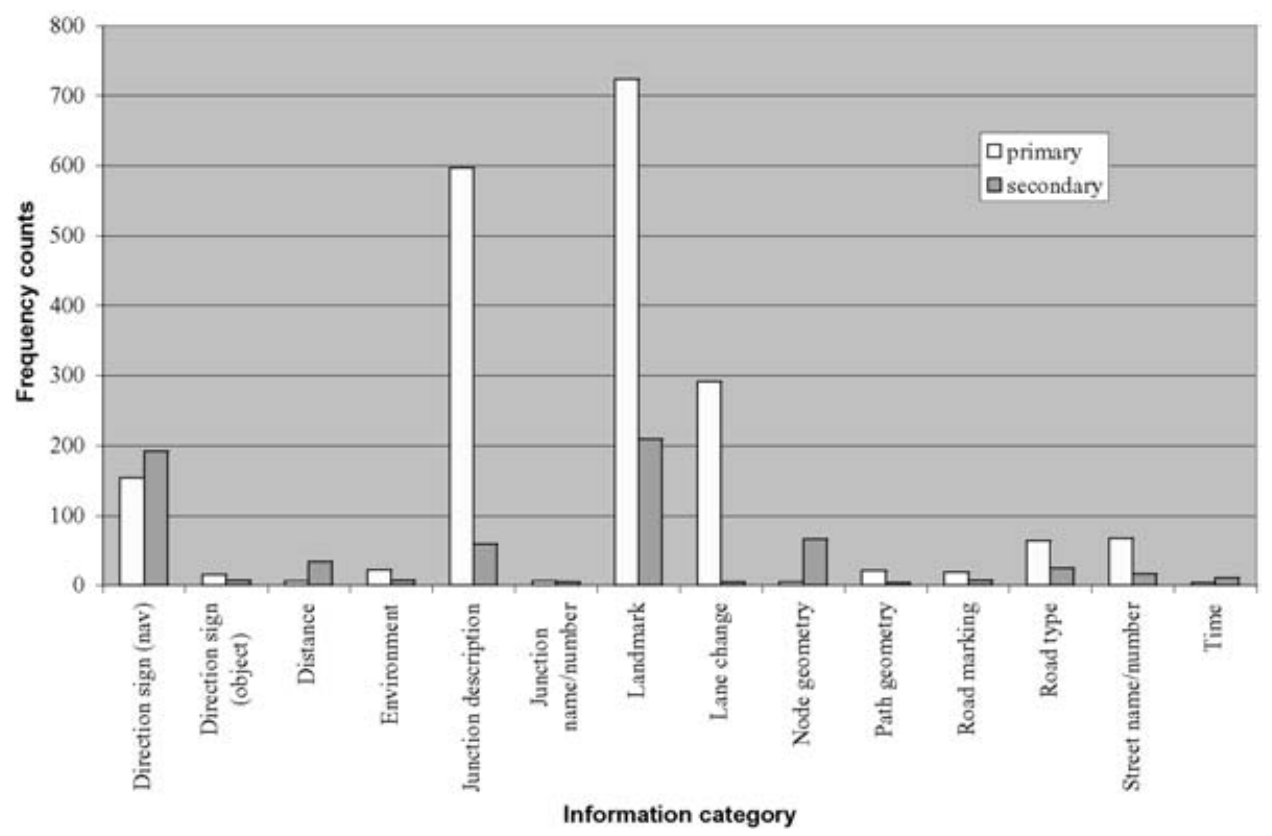

Figure 4. The use of general information categories as primary (required) or secondary (redundant) information, for all participants.

3.5. Information in relation to route characteristics. An analysis was undertaken of the information used at each particular decision point (manoeuvre), and between these manoeuvres. Space precludes presentation of these results; however, there was considerable variability apparent, due to the availability of information, and the participants' assessment of its value, based on the context of each manoeuvre. For example at one manoeuvre (merging onto a dual carriageway), lane change information and direction signs were the most used information; at another (going straight over a crossroads with traffic lights), landmarks were used to the almost total exclusion of all other information; at a third manoeuvre (a complex roundabout leading onto a ring road), there were a total of 10 different categories of information used, with no clear preferences emerging.

4. DISCUSSION. The aims of this study were to understand the information needed by a driver to navigate successfully a range of complex urban routes. Figure 2 shows that landmarks were the most frequently used category of information, being used more often than direction signs and junction descriptions by both the cognitive map and video participants. These results are consistent with the survey findings of Burns (1997). The frequent use of landmarks is due to a number of factors - the landmarks category included a wide range of different types of information, and therefore the availability of information within this category was high. (The list of landmark categories included traffic lights, bridges, pedestrian lights, petrol stations, public houses, parks, restaurants, post boxes, phone boxes, plus a wide range of other buildings.) In addition, landmarks are traditionally used (at least within the UK) to help provide navigation directions. It is possible that if this study 
was repeated in other countries (e.g. USA), landmarks would be used less frequently and other descriptions such as road names and numbers, block numbers and compass directions would be used instead. Junction descriptions were the next most frequently referred to category; this category included descriptions of the type of junction such as 'roundabout', 'T junction', 'cross road', but excluded descriptions of the appearance or nature of the junction such as 'large', 'mini', or 'sharp', 'gentle' (these were included within the 'node geometry' category). Since the navigation task can be conceptualised as the travelling between points of navigational uncertainty, the description of these points of navigational uncertainty (usually junctions) is one of the easiest ways of describing a route. The lack of availability of a junction name or number for many junctions resulted in the low frequency count for this category.

It is interesting to note that distance information was used infrequently, and particularly so by the video group of participants. This underlines the general difficulty that humans have in judging distances, and particularly the difficulties of mapping visual representation of routes onto distance judgements. Distance information is commonly used within many map representations and navigational aids; the results of this study suggest it may not be particularly useful.

Direction signs were used both for the navigation information contained on them, but also as objects that could be referred to, and two separate coding categories were used to represent these two different ways of referring to them. (It could be argued that in the latter case, the road sign became a 'landmark', but to enable comparison, they were coded as a separate category.) Direction signs used for their navigation information were used relatively frequently, but more frequently by the video group. This implies that their visual characteristics are relatively stronger than the participants' cognitive associations with them, i.e. that even local experts do not remember the placement of, and information on, all useful direction signs. One of the routes used within the study included a section of the Coventry Ring Road, and one of the most frequent uses of the road sign category was the guiding of drivers around the ring road by giving them instructions such as 'follow the signs for Birmingham'.

Information concerning lane changing and lane positioning was seen as important by both participant groups; this was most frequently used at large roundabouts, multilane traffic light controlled junctions, and for entering and exiting a ring road section.

It is interesting to note that many information categories were used similarly by the cognitive map and video participants. This suggests that these information categories are similar in terms of their visual prominence and the association that local experts have with them. The main exceptions to this were the 'street name/number' category, which was used much more frequently by the cognitive map group, and 'road markings' and 'direction signs as objects', which were used by the video but not the cognitive map group. This can be explained by consideration of the availability of the information on route, and the relative visual prominence of this information.

An indication of the relative importance of different types of navigation information is given in Figure 4. The three most common categories of primary information were landmarks, closely followed by junction descriptions and lane change information. If these categories of information were not available to a driver, then based on the directions generated by the study participants, a driver would not have been able to navigate successfully at most of the decision points. It has to be remembered however, that all three of these categories were quite broadly defined. Where junction 
descriptions were given, these were virtually all used as the main piece of information used to describe the manoeuvre. In about $70 \%$ of cases, landmarks were used as the primary navigation information for a particular manoeuvre. In contrast, direction signs used for their navigation information were used both as essential information at a manoeuvre but also as additional information to reinforce the primary navigation information. A typical use of a direction sign was an instruction of the form 'turn left at the roundabout, following signs for the industrial park'.

To understand how information is used by drivers for navigation purposes it is necessary to understand the nature of the task that the information is supporting. The graph shown in Figure 3 shows how different information categories are used in relation to the simple model describing the main features of the navigation task (Figure 1). It can be seen that in virtually all instances, the categories of navigation information are used to identify a manoeuvre or a progress point en-route. The main exceptions to this are references to lane positioning or lane changing which, as might be predicted, are used in preparation to a manoeuvre (decision point) and street names/numbers, which are used to help a driver confirm that they have completed the correct turning.

As outlined in Section 2, there are many potential methodological issues relating to a study of this nature. This study attempted to maximise the usefulness and validity of the results generated via the careful selection of participants and navigation tasks (routes), the use of 'video' and 'cognitive map' representations of the route, a comprehensive data capture process and coding taxonomy, and the use of theoretical models to explain and generalise the results. However, it is possible that the form of the instructions generated (i.e. written textual descriptions) may have influenced the type and amount of navigation information identified. For example, useful navigation information may have been excluded from the written instructions because it was difficult or lengthy to describe in textual terms (as opposed to being easily sketched). In addition, particular participants may have had individual preferences for either textual or graphical descriptions (as well as preferences for navigation information) and this may have influenced the information they identified.

5. SUMMARY AND CONCLUSIONS. The study has shown how different categories of information are used to enable navigation by an unfamiliar driver around some complex urban routes. Although the results are only of direct relevance to the particular routes used within the study (due to the specificity of the information), the results should have applicability to urban navigation in general due to the varied nature of the routes chosen. Within a driving context, landmarks, junction descriptions, lane information and direction signs emerged as the most important categories of information, while distance information was perceived to be of little value. Most of these information categories were used as a primary piece of navigation information, i.e. where the omission or inaccuracy of this information would probably result in a navigation error or considerable driver uncertainty. Information was used to identify both manoeuvres and progress points, with lane change information being used in the run-up to a manoeuvre (preview), and street names and numbers being used to confirm that a correct turning had been taken.

There are several implications that arise from the results of this study in terms of the design of navigation aids. The categories of information found useful relate directly to the information needed on a navigable database. The fact that most information was 
used as primary information (i.e. there was generally little redundancy built into the navigation instructions used) has implications for the presentation of this information to the user, especially modality of presentation (auditory/visual) and display design. The model of the navigation task, and the mapping of information to these task aspects, can be used to help specify the requirements for information prior to, at and after manoeuvres, and hence the timing of the presentation of information in relation to key decision points on a route.

This study emphasises the need to design navigation aids from a user rather than a technological perspective. Distance information may be relatively easily and accurately calculable, and junction descriptions are relatively stable, i.e. the information quality associated with these will have a relatively slow decay rate. However the collation and maintenance of navigable databases containing information on direction signs, and landmarks in particular, presents a considerable challenge, due to the diversity of this data, lack of availability centrally, and the rate at which some of it becomes out of date and inaccurate. For a driver, information on lane positioning is important; although not necessarily ensuring better navigation, effective lane change information is likely to help minimise driver workload and aid safety in relation to other road users.

In summary, the information used for navigation is varied and complex, and there are considerable challenges involved in designing effective navigation aids. However, irrespective of the navigation environment, it is possible to take a user-centred view and attempt to understand what information is used, how important it is, and when it is needed.

\section{REFERENCES}

Burnett, G. (2000). 'Turn right at the traffic lights': The requirement for landmarks in vehicle navigation systems. This Journal, 53 (3), 499-510.

Burnett, G., Smith, D. and May, A. (2001). Supporting the navigation task: characteristics of 'good' landmarks. Contemporary Ergonomics 2001: Proceedings of the Annual Conference of the Ergonomics Society. Taylor \& Francis.

Burnett, G. E. (1998). 'Turn right at the King's Head' : Drivers' requirements for route guidance information. Loughborough University, UK.

Burns, P. (1997). Navigation and the older driver. Human Sciences. Loughborough, UK, Loughborough University.

Chown, E., Kaplan, S. and Kortenkamp, D. (1995). Prototypes, location, and associative networks (PLAN): Towards a unified theory of cognitive mapping. Cognitive Science, 19, 1-51.

Christou, C. and Bulthoff, H. H. (2000). Perception, representation and recognition: A holistic view of recognition. Spatial Vision, 13 (2-3), 265-275.

King, G. F. (1986). Driver performance in highway navigation tasks. Transportation research record (1093), pp. $1-11$.

Mark, D. M. (1989). A conceptual model for vehicle navigation systems. Vehicle Navigation and Information Systems, IEEE.

Passini, R. (1984). Spatial representations, a wayfinding perspective. Journal of environmental psychology, 4, 153-164.

Streeter, L. A. and Vitello, D. (1986). A profile of drivers' map-reading abilities. Human factors, 28 (2), 223-239.

Wickens, C. D. (1992). Engineering Psychology and Human Performance. New York, Harper Collins.

Wierwille, W. W., Antin, J. F., Dingus, T. A. and Hulse, M. C. (1989). Visual attentional demand of an incar navigation display system. Vision in vehicles II. A. G. Gale, London, Elsevier Science, pp. 307-316.

Zhai, S. (1991). An information structural model of vehicle navigation and its implications. IEEE/SAE Conference on Vehicle Navigation and Information systems (VNIS '91). Dearborn, Michigan, USA. 